\title{
Used Cooking Oils as a Source Material for Biodiesel Production: Case Study for Kitwe Town, Zambia
}

\author{
Mwema Wanjiya ${ }^{1,}$, Misozi Makangila ${ }^{2}$, Lloyd Mukosha ${ }^{1}$ \\ ${ }^{1}$ Chemical Engineering Department, School of Mines and Mineral Sciences, The Copperbelt University, Kitwe, Zambia \\ ${ }^{2}$ Environmental Engineering Department, School of Mines and Mineral Sciences, The Copperbelt University, Kitwe, Zambia \\ Email address: \\ mwema.wanjiya@cbu.ac.zm (M. Wanjiya),misozi.makangila@cbu.ac.zm (M. Makangila), mukoshal@cbu.ac.zm (L. Mukosha) \\ ${ }^{*}$ Corresponding author
}

\section{To cite this article:}

Mwema Wanjiya, Misozi Makangila, Lloyd Mukosha. Used Cooking Oils as a Source Material for Biodiesel Production: Case Study for Kitwe Town, Zambia. International Journal of Economy, Energy and Environment. Vol. 3, No. 4, 2018, pp. $32-37$.

doi: $10.11648 /$ j.ijeee.20180304.11

Received: August 10, 2018; Accepted: September 26, 2018; Published: October 19, 2018

\begin{abstract}
The escalating prices on the world market, depreciation of fossils fuel reserves and environmental concerns has lead to the quest for the alternatives sustainable renewable energy sources. The past decades have witnessed innovations developed to produce biodiesels from various sources such as Groundnuts, Soya beans, Palm oils, Canola, Sunflower, Castor nuts and Jatropha plants and animal fats. However, most of these raw materials are competitive as food sources in human food chain. This research assesses the use of Used Cooking Oils (UCOs) from food outlets in Kitwe Town, Zambia as source for biodiesel production. Of equal importance is the assessment of environmental impact of the current waste management practices employed in disposal of UCOs. Data was obtained by administering questionnaires to various food outlets. The study revealed that approximately $8500 \mathrm{~L} /$ year of UCO would be generated from the sampled area. Fast food outlets accounted for $76 \%$ of the overall UCOs production in the sampled area. It was found that UCOs were mainly disposed through drainage into Municipal Sewers with the possibility of fatberg generation. Reuse of the UCO by the correspondents was a common practice and any leftover was disposed into the environment. The results of this study indicated the UCOs could be a major source material for biodiesel production.
\end{abstract}

Keywords: Used Cooking Oils, Biodiesel, Management, Generation

\section{Introduction}

The escalating prices on the world market, depreciation of fossils fuel reserves and environmental concerns has led to the quest for the alternative sustainable renewable energy sources. The past five decades has witnessed technological innovations developed to produce green energies mostly the biodiesels. This has been to meet the increasing energy requirements, as an alternative for diesel oil for internal combustion engines. Biodiesels offer a very promising alternative to diesel oil since they are renewable and have similar properties. It is a promising substitute for fossil fuels and it poses remedial solutions to environmental concerns. Biodiesel is a liquid biofuel produced by a chemical processes from vegetable oils or animal fats and alcohol that can be waste in diesel engines, alone or blended with diesel oil, [1, 2, 3].
The biodiesel is produced from so many sources such as groundnuts, soya beans, palm oils, algae and including Used Cooking Oils (UCOs) by a process transesterification [4]. In this process the three chains of fatty acids of each triglyceride molecule reacts with an alcohol in the presence of a catalyst to obtain ethyl or methyl esters. This yields mono-alkyl methyl esters (biodiesel) and glycerine. This production process is catalysed either homogeneous or heterogeneous.

Commercial biodiesel is sold as a blend with regular ultralow sulphur diesel (ULSD). The use of pure biodiesel can be described as B100 (100\%) or neat biodiesel or blended with fuel diesel, described as B20 which represents a $20 \%$ biodiesel and $80 \%$ diesel likewise B40 which represents a $40 \%$ biodiesel and $60 \%$ diesel [9]. Biodiesel is more sustainable and environmentally friendly as compared to the fossil fuels. Advantages of biodiesel include; low toxicity, 
degrades more rapidly than diesel fuel, minimal environmental consequences in terms of biofuel spills and lower emissions of contaminants such has Carbon Monoxide, Particulate Matter, Polycyclic Aromatic Hydrocarbons, aldehydes [1]. Also it is a renewable energy, lower health risks in terms of the emissions of carcinogens substances, no sulphur emissions, higher flash point (100oC minimum) and may be easily blended with fuel at any proportion both fuels may be mixed during fuel supply to vehicles. The disadvantages of biodiesel include; slightly higher nitrous oxides emissions, slightly higher fuel consumption due to lower calorific values, higher freezing point which means that inconveniences in cold climate, it is less stable therefore long term storage of more than six months is not suitable. However, these setbacks can easily be overcomed.

Currently most biodiesel is produced from vegetable oils (soya beans, Sunflower, groundnuts, castor nuts and Jatropha plants) [5] and animal fats, there are concerns that biodiesel feedstock may compete with food supply in the long-term. According to the World Food Organisation (WFO), globally there is food crisis especially among the third world countries where most people live below the poverty datum line [6]

Hence, this study focuses on the feasibility of utilising UCOs as the substantial feed stocks for biodiesel production in Kitwe City, Zambia. It is suffice to say that the rate of generation of UCO has greatly increased in Africa and Zambia as well with growth in the fast food industry. This scenario has a potential create enough feedstock and employment for the populations [7]. In addition, the study focuses on the current management of UCO by the fast food industry in Kitwe.

The City of Kitwe is found on the Copperbelt Province in Zambia. It covers an area of $777 \mathrm{Km} 2$ and has a population of 522, 092 with an approximated $3.3 \%$ annual growth rate [15].

\section{Literature Review}

Zambia's total domestic market consumption was 753, 652

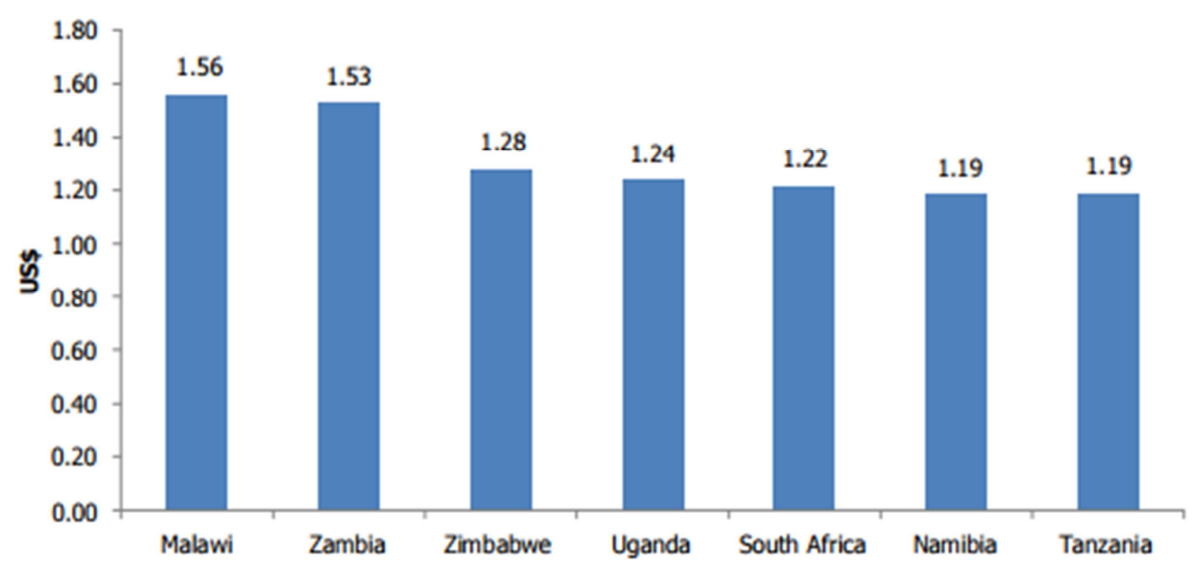

Figure 1. Regional Prices of Diesel in US\$ / Litre as at October, 2011 [16].

In the currently National Developmental Plan of 20172030, the government of Zambia is encouraging research in renewable energies and it has been placed as one of the key metric tonnes in the year 2010 with diesel being the highest consumed [16] as shown in Table 1. Zambia is also prone to the negative impacts of high prices of fossil fuels and environmental issues emanating from the use of this energy source. The depreciation and high cost of explorations of fossil fuels has resulted in high prices for the fossils fuels, this has affected a number of industries such as the aviation, automobiles and chemical industries.

Table 1. Domestic Market Consumption of Fossil Fuels in Zambia [16].

\begin{tabular}{ll}
\hline Product & Percentage Consumption \\
\hline Diesel & 66 \\
Unleaded Petrol & 21 \\
Kerosene & 2.3 \\
Jet A1 & 3.9 \\
Avgas & 0.13 \\
LP $^{*}$ Gas & 0.25 \\
HFO** & 6.2 \\
LFO $^{* * *}$ & 0.22 \\
\hline
\end{tabular}

"LP - Liquid Petroleum, ${ }^{* *}$ HFO - Heavy Fuel Oils, ${ }^{* * *}$ LFO - Light Fuel Oil

This has resulted into negative spiral economic impacts on the livelihood of the people. The country in February, 2018 witnessed another rise in the pump fuel price Petrol, Kerosene, Diesel and Liquefied Sulphur Gas (LSG) by the Energy Regulation Board costing K 13.78 , K8.85, K12.01 and K14.30 respectively [10], with an exchange rate of 1 US\$ to K 10.

High fossil fuels prices is quiet high in Zambia compared to the other countries in the Southern African Region as shown in Figure 1 below. This can be attributed to a number of factors such as being a landlocked country thereby cost of transportation is high and involvement of middlemen in the supply chain. In addition high taxes charged by government on fuel [16] have led to this increased pump fuel price. However, Zambia just like any other country can overcome this problem by exploring on other renewable alternative energy sources. pillars of national development strategies implemented by the Ministry of Energy. Zambia Is currently producing biofuels from sources such as Soya beans, Sunflower, groundnuts. But 
these raw materials are all edible to human beings and therefore, they are not sustainable in a long run. Zambia has the potential of generating biodiesel from Used Cooking Oils (UCOs) which can be sourced from various food outlets.

Globally the Fast Foods Industry has witnessed enormous growth and Zambia is not an exceptional. It has become a lucrative business ventures for most investors because of the huge profits in this particular industry and its future prospects are rated high. Frying of food by restaurants, catering facilities, hotels and Fast Food outlets is a common feature. Using fresh vegetable cooking oil for producing quality food produced is a must for the food to be more delectable. The cooking oil has to be replaced after sometime and hence the generation of used cooking oil (UCO) is inevitable. Studies have shown that an estimated 15 Litres of used cooking oil per day can be generated from a Fast Food business in Malaysia [8] and 378 million litres per day in the United States of America [11]. Apart from commercial properties (Canteens), UCO is generated at household and industrial level (Food Processing). The characteristic especially in terms of appearance of UCOs varies depending on the type of food that is being processed as Figure 2 below.

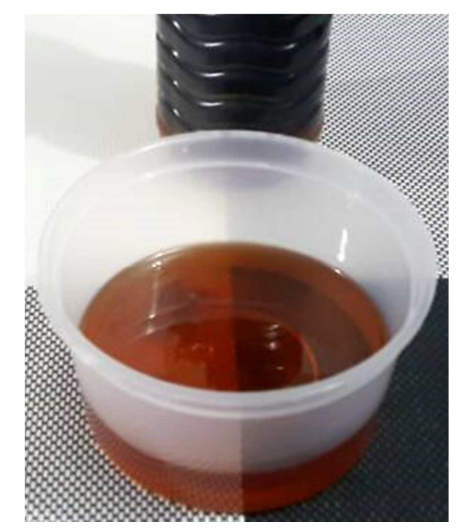

(a)

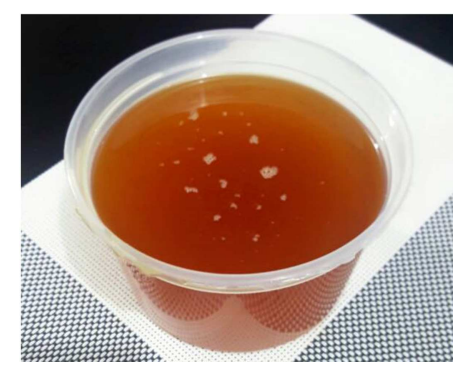

(b)

Figure 2. (a) Used cooking after frying fish - Darker in Colour (b) Used Cooking after frying potato chips- $A$ bit lighter.

The use of UCOs in biodiesel production has been explored by many researchers $[8,12,4,13]$. This option is helpful for waste management and also removes the concern of competition with edible food [7]. In addition, the use of UCO's in biodiesel generation seems to be one of the ways of reducing the production cost of biodiesel [14]. If UCO is not properly disposed it may lead to catastrophic environmental upsets such as surface water contamination and land pollution. Pouring of UCOs down kitchen sinks can cause blockages and overflows of sewer systems. The presence of oils in wastewater effluent can add to the cost of wastewater treatment [9] as additional treatment units are required.

This aim of this study was indentifying UCO's as an alternative substantial feed stock for biodiesel production in Zambia, with Kitwe City as a sample study area. Also it was of interest to evaluate the environmental impact of the current UCO's disposal management practices by the generating sources. Kitwe City is one of the major urban social economic hub of Zambia. Using Kitwe as a study area, the researchers strongly believe the trend would be similar much across other urban cities in Zambia.

\section{Methodology}

Although at household level there is generation of UCO the collection potential is minimal. Thus, the study focused on capturing reliable estimates of UCO generation and disposal practises from most relevant generating sources where UCO becomes available in Kitwe. To this effect, the major source of UCO is Fast Foods Outlets and Cantering Facilities. The data collection tools were consultation meetings with the key stakeholder (Local Municipality, the Kitwe City Council) and distribution of questionnaires to managers at UCO generation sources. Consultations with the local municipality sought to establish the numbers of registered restaurants in Kitwe and the existing regulations on UCO disposal. Questionnaires were designed to address UCO aspects that include; daily generation capacity, the storage mechanisms and methods of disposal.

\section{Results}

\subsection{Sources and Types of Used Cooking Oil}

Figure 3, indicates that $76 \%$ of the Used Cooking oil is from Fast Food Outlets, $24 \%$ was from Catering Facilities. All the sampled locations within Kitwe Town, indicated that vegetable oils is used when preparing foods unlike the use of animal fat. Different type of vegetable oils are on the market which include Sunflower oil, Soya Beans, Groundnut, Canola oil, Palm Oil and Cotton Oil. The respondents were asked the type of vegetable oil they use. Figure 4 shows that $62 \%$ of the respondents use Sunflower and $38 \%$ indicated that they use Soya Beans oil. No respondents indicated the use of the other types of oil.

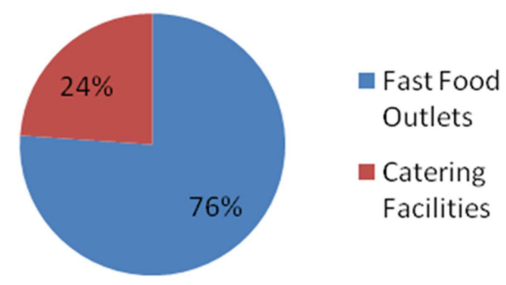

Figure 3. Sources of UCOS. 


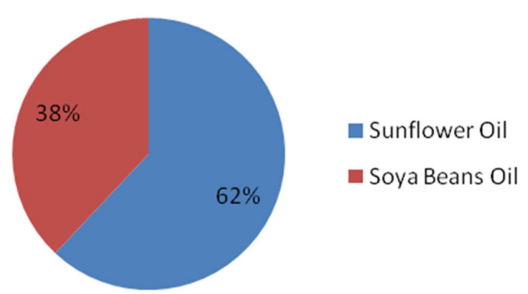

Figure 4. Types of UCOs.

\subsection{Fresh Cooking oil Vs. Generated Cooking Oil}

Twenty points indicated (A-S) in Figure 5 below were used to obtain data. One sampling point not indicated in Figure 5 was short on information on Fresh cooking oil used against the Used cooking oil.

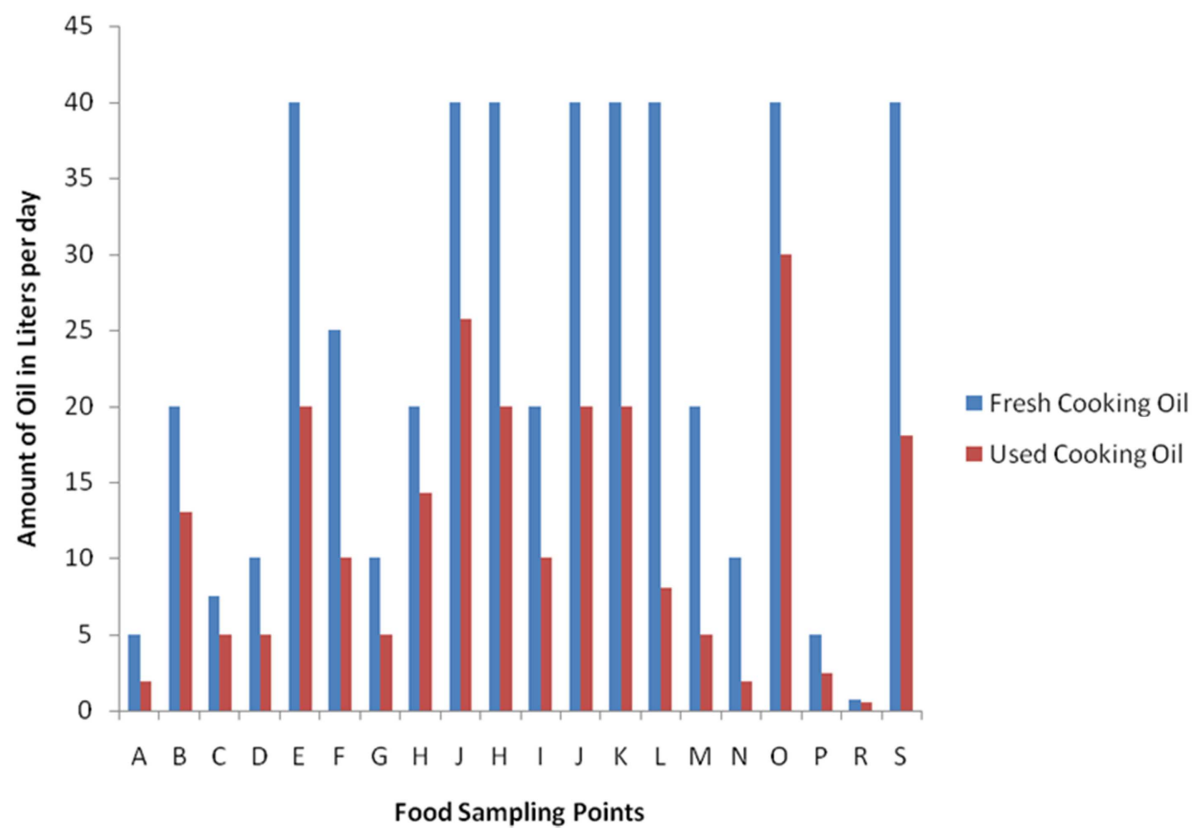

Figure 5. The amount of fresh cooking oil that is used during food preparation against theh generated used cooking oil by the various Food Outlet that where sampled within Kitwe.

\subsection{Current Management Systems of Used Cooking Oil by the Food Industry}

All respondents indicated that they store UCO in plastic containers for some time before disposal options are made. The methods of management which are employed thereafter are shown in Figure 6 below.

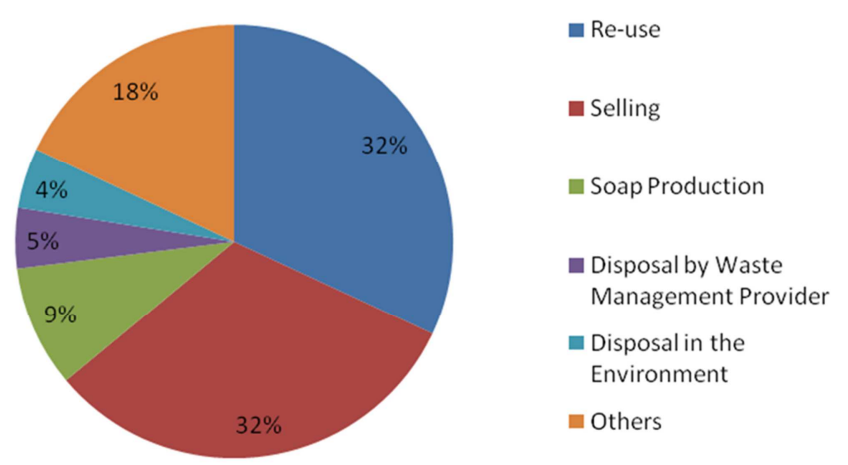

Figure 6. Current Management of Used Cooking Oils.

\section{Discussion}

This research study has affirmed to what was alluded to in the literature review above that the food industry is growing at a fast rate. The results obtained in Figure 3 above, have showed that the Fast Food Outlet are leading with $76 \%$ as compared to the Cantering Facilities at $24 \%$. This result is expected owing to the fact that with an increase in monthly income of most of the households and changes in lifestyles, Fast Food Outlets offer readily available meals for most families in this particular category. This phenomenon has a great potential for UCO generation for the biodiesel industry.

Results obtained in Figure 4, have revealed that Sunflower is the most preferred fresh cooking oil used in the food industry accounting for about $62 \%$ in surveyed sampling points. It is very important to know the type of the Used Cooking Oil because different type of vegetable oil have different physical characteristic such as density, kinematic viscosity, fatty acid profiles [17], which will determines appropriate and effective yields of biodiesel in the production of the biodiesel.

The obtained result revealed in Figure 5 above of the selected 20 sampling points (A-S), shows that of the 465.25 $\mathrm{L} / \mathrm{d}, 232.01 \mathrm{~L} / \mathrm{d}$, was generated as used UCO from the frying of various food stuffs like meat, chickens, fish and potato chips. This figure accounts for almost $50 \%$ of fresh cooking oils used in the cooking processes per day. With these figures all process being equal, the potential UCO cooking oils to be 
generated per week, month and annually is $1624.07,6960.3$ and 84683 Litres respectively. Noted according to the local Municipality, there is a total of hundred ninety potential UCO generators across the city of Kitwe. For this reason, the estimated values would be high. Therefore, there is no doubt that source of this raw material for the manufacturing of biodiesel is attainable using the methods of transeterification [4] and methods revealed in the previous research study by [18].

Production of biodiesel is achievable from the UCO, as showed in previous research by [12], the research revealed the production of biodiesel from UCO from frying of fritters in Kolkata in India.

Zambia is a major consumer of fossil diesel accounting to about $66 \%$ and the second highest in terms fuel pump price in the Southern Africa Region as shown in the Table 1 and Figure 1, in the literature above. Therefore, the production of biodiesel from readily and cheap available used cooking oils could mitigate this situation.

The results obtained in Figure 6 above, shows the management of the UCO by the generators. It is suffice to say that the majority of the generators in Kitwe could not avail full details to this research on disposal mechanism of the UCOs. This raised major concerns to this particular study. The results only revealed that of total sampling points, only $5 \%$ submitted their UCOs to waste management service providers for further disposal to designated waste disposal sites. Another concern revealed by this study is that $32 \%$ is sold to workers for further re-use and $32 \%$ is sold for other uses. Previous research study by $[19,20,21]$, revealed that when oil is heated to temperatures of above $170{ }^{\circ} \mathrm{C}$ to $220^{\circ}$ $\mathrm{C}$ in the presence of oxygen, oil undergoes thermal, physical and chemical degradation reaction. This scenario makes the UCO to have viscosity and a darker colour.

The degraded products may include fatty acids, hydroperoxides and thriglycerides which are so harmful to human beings. Research by [22] revealed that the amount of degradation increases with the duration of heating at high temperatures, therefore, the more the oil is reheated the more of these toxic compounds are formed. These toxic compounds are harmful to human beings once consumed and some of the effects are hypertension, atherosclerosis and endothelial dysfunction [24]. Also previous research by [23, 25], revealed that prolonged heating of cooking oils at high temperatures generates lipid peroxidation. This phenomenon leads to peroxidation of membrane macromolecules contributing to mutation and genotoxity which may lead to cancers. Therefore, as long as there are no proper mechanisms for the disposal of the used cooking oils, the health risk of reusing them is huge to ignore for the well being of the workers and the general population.

The results only showed that only $9 \%$ of the used cooking oils were used for soap production, this number is so minimal. For that reason, this research finding affirms that improper usage of this commodity is high. This scenario is alarming to healthy being of the population. The results also revealed that $4 \%$ of the generators directly disposed the
UCOs in the environment such as drainage system and on land. There is high possibility that the percentage maybe high than this given figures. Great negative environmental implications may arise from the way these UCOs together with the fatty acids and grease from the frying meats and chickens end up being poured down the drain or the ground. This could include potentially contaminating underground water, cause blockages of drainage and sewer pipes and consequently increases the cost of waste water treatment respectively.

\section{Conclusion}

This research has revealed that there is a great potential in Zambia to produce biodiesels from the UCOs. The source of the raw material is readily available as revealed by this research finding. The obtained trajectory figures of per week, month and annually is 1624.07, 6960.3 and 84683 Litres respectively of UCOs makes this project feasible. If the government undertakes sensitisation and deliberate policies on the management of UCOs towards the biodiesel production, the source base of UCOs will be adequate. The usage of the UCOs in the manufacturing of biodiesel will minimise the dependence on Soya beans, Ground nuts, Palm Oils which are competitive in the food chain. Also, the production of biodiesel from UCOs could provide an alternative to the disposal of these oils. This phenomenon once implemented could potentially reduce the pump price of the diesel thereby growing economy of Zambia. Other countries are taking such initiatives very seriously, for example Italy is heavily conducting research on generating biofuels from algae by the year 2030 [26].

Apart from this there are also environmental benefits such as being an eco-friendly fuel, consequently, reduced emissions of harmful combustion gases into the environment. Spillages in the drainage systems will be minimised, thereby, less contamination of the groundwater systems blockages of the sewerage pipes. The negative healthy risks associated with aspects of the people consuming the UCOs will be mitigated.

\section{References}

[1] A. E Atabani, T. M. I. Mahlia, H. H. Masjuki, I. A. Badruddin, H. W. Yussofu, W. T. Chong and K. T. Lee, (2013). A comparative evaluation of physical and chemical properties of biodiesel synthesized from edible and non edible oils and study on effect of biodiesel blending. Journalhomepage:www.elsevier.com/locate/energy. Energy 58 (2013) 296-304.

[2] N. Lamba, S. Adhikari, J. M. Modak and Madras, (2018). Catalytic synthesis of fatty acid methyl esters from Madhuca indica oil from supercritical menthanol. Energy Conversion and Management. Vol. 173, page 412-42.

[3] A. Carlos, F. Guerrero, G. R. Andres and E. S. Fabio (2011) Biodiesel production from waste cooking oil. National University of Colombia, Colombia. 
[4] H. Fukuda, A. Kondo and H. Noda, (2001). Biodiesel Fuel production by transesterfication of oils. J. Biosci Bioeng 92 (5): 405-416.

[5] T. M. Y. Khan, A. E Atabani, I. A Badruddin, A. Badarin, M. S Khayoon, S. Triwahyono, (2014). Renewable and Sustainable Energy Reviews, 37, page $840 \quad-851$. Journalhomepage:www.elsevier.com/locate/rser.

[6] Global Report on Food Crises 2018- World, https://reliefweb.Int/report/global-report-food-crises-2018.

[7] L. Yang, M. Takase, M. Zhang, T. Zhao, X. Wu (2014). Potential non-edible oil feedstocks for biodiesel production in Africa: A survey. Renewable and Sustainable Reviews. Vol. 38, pages 461- 477 .

[8] N.H. Abdullah, S. H. Hasan, N. R. M Yusoff (2013). International Journal of Materials Science and Engineering. Vol. 1. 94 -99.

[9] M. Arbelaez, M. Rivera, (2007). Diseno Conceptual de un para la Obtencion de bodiesel a partir de algunos aceites vegetales Colombianos. Unversidad Eafit. Medellin.

[10] [10]Fuel prices increased. https://www.znbc.co.zm/fuelprices-increased/ (Accessed on 19/03/18).

[11] A. Radich (2006). Biodiesel performance, costs and use. US Energy Information Administration.

[12] N. Banerjee, R. Ramakrishrian, T. Jash (2014). Biodiesel Production from Vegetable oil collected from shops selling fritters in Kolkata. 4th International Conference on Advances in Energy Research 2013.

[13] H. T. Yie M. A. Abdullah, C. Nolasco-Hipolito, H. Taufiq-Yap (2015). Waste ostrich- and chicken-eggshells as heterogeneous base catalyst for biodiesel production from Waste cooking oil: Catalyst characterization and biodiesel yield performance. Applied Energy. 58 -70.

[14] I. Boumesbah, Z. Hachaïchi-Sadouk and A. Tazerouti (2014). Biodiesel production from waste frying oil and determination of fuel properties. Revue des Energies Renouvelables SIENR'14 Ghardaïa 109 - 113109.

[15] Kitwe City Council. Accessed: http://www.kcc.gov.zm/aboutkitwe/.
[16] Energy Regulation Board, 2012. Report on Status of the Petroleum Industry.

[17] A. Karmakar, S Karmakar and S. Mukherjee S (2010). Properties of various plants and animals feedstocks for biodiesel production. Bioresource Technology 2010; 101:7201-7210.

[18] AV. Tomasevic and SS. Siler-Marinkovic (2003). Methanolysis of used frying oil. Fuel Process Technology 2003; 81:1-6.

[19] R. G. Moreira, M. E Castell-Perez, and M. A Barrufet, M. A. (1999). Deep-Fat Frying: Fundamentals and Applications. Aspen Publishers, Gaithersburg, MD.

[20] E. Choe and D. B. Min, ( 2007). Chemistry of Deep-Fat Frying Oils. Journal of Food Science, 72: R77-R86. doi: 10.1111/j.1750-3841.2007.00352.x.

[21] N. I. Acquah Y. G. Obeng Y. G, and E. Mensah (2016). Repetitive Use of Vegetable Cooking Oil and effect on Physico-Chemical Properties - Case of frying with Redfish (Lutjanus fulgens). Science and Technology 6(1): 8 - 14: DOI: 10. 5923/j.Scit. 20160601.02.

[22] A. Romero, S. Bastida, and F. J. Sanchez-Muniz, (2006). Cyclic fatty acid monomer formation in domestic frying of frozen foods in sunflower oil and high oleic acid sunflower oil without oil replenishment. Food and Chemical Toxicology44: 1674-1681.

[23] A. Lapointe, C. Couillard and S. Lemieux (2006). Effects of dietary factors on oxidation of low-density lipoprotein particles. Journal of Nutritional Biochemistry, 17(10): 645-58.

[24] MJ. Williams, W. H. Sutherland, M. P. McCormick, S. A. de Jong, R. J. Walker, and G. T. Wilkins, (1999). Impaired endothelial function following a meal rich in used cooking fat.

[25] C. M. Yang, A. A. Grey, M. C. Archer, W. R Bruce (1998). Rapid quantitation of thermal oxidation products in fats and oils by 1H-NMR spectroscopy. Nutr Cancer, 30(1): 64-68.

[26] D. Gambelli, F. Alberti, F. Solfacelli, D. Vairo and R. Zanoli, (2017). Third generating algae biofuels in Italy by 2030 A scenario using Bayesian networks. 